\title{
The Relationship Between Resilience and Self-Reported Function in Patients After Total Joint Arthroplasty: A Critically Appraised Topic
}

\author{
Ansley E. Swann, ATC, LAT, Rachel R. Kleis, MS, ATC, LAT, and Johanna M. Hoch, PhD, ATC, LAT \\ University of Kentucky
}

\begin{abstract}
Clinical Question: Is there a relationship between resilience and self-reported function in patients who underwent a total joint arthroplasty? Clinical Bottom Line: There is inconsistent, good-quality Level II evidence that investigates the relationship between resilience and self-reported function in patients after joint arthroplasty.
\end{abstract}

Keywords: arthroplasty, outcomes, psychology

\section{Clinical Scenario}

Osteoarthritis $(\mathrm{OA})$ is a degenerative joint disease that causes disability in much of the middle-aged and older adult populations. ${ }^{1}$ Patients with OA often have severe physical limitations that prevent them from returning to work or maintaining their normal activity levels, and also experience depression and anxiety. ${ }^{2}$ Once conservative treatments for OA have failed, a total joint replacement surgery, or arthroplasty, is often warranted. ${ }^{3}$ Total joint arthroplasty frequently leads to improvement in overall health; however, poor psychological outcomes such as depression and anxiety are prevalent. ${ }^{4,5}$ Resilience is defined as the ability to adapt to significant sources of stress or trauma. ${ }^{6}$ One study that examined resilience quantitatively in active duty military populations demonstrated that increased resilience positively impacted quality of life and decreased suicide risk. ${ }^{7}$ However, resilience has been examined sparingly in the orthopedic population. Examples of quantitative investigations include those in the total joint arthroplasty patient population ${ }^{5,8,9}$ and qualitative investigations in the post anterior cruciate ligament (ACL) reconstruction population. ${ }^{10}$ While there is limited research evaluating the relationship between resilience and self-reported function after musculoskeletal injury, there have been studies that have examined this relationship in the patients who have undergone total joint arthroplasty. Therefore, the purpose of this Critically Appraised Topic (CAT) was to critically appraise the available evidence that examined the relationship between resilience and self-reported function in patients who underwent a total joint arthroplasty.

\section{Focused Clinical Question}

Is there a relationship between resilience and self-reported function in patients who underwent a total joint arthroplasty?

\section{Search Strategy}

A computerized search was completed in September 2019 (Figure 1). The search terms used were:

The authors are with the Department of Athletic Training and Clinical Nutrition, University of Kentucky, Lexington, KY, USA. Hoch (Johanna.hoch@uky.edu) is corresponding author.
- Patient/client group: patients who underwent arthroplasty (total joint surgery OR total knee arthroplasty OR total shoulder arthroplasty OR total hip arthroplasty)

- Intervention/assessment: resilience

- Comparison: not applicable

- Outcome: patient reported outcomes OR patient outcomes OR outcomes

\section{Sources of Evidence Searched}

- EBSCOhost

- Medline

- Academic Search Complete

- CINHAL

- SPORTDiscus

- PsycINFO

- Additional resources were obtained via review of reference lists and hand searches.

The criteria for study selection were as follows:

\section{Inclusion Criteria}

- Studies that examined the relationship between self-reported resilience and self-reported function in patients that underwent total joint arthroplasty

- Studies that utilized a self-reported resilience scale, such as the Brief Resilience Scale (BRS) ${ }^{11}$ or Connor-Davidson Resilience Scale, ${ }^{12}$ to measure resilience

- Studies that utilized patient-reported outcome measures (PROs) to capture self-reported function

- Studies that included adults 18 years and older

- Peer reviewed studies published in the last 10 years

- Studies published in English

\section{Exclusion Criteria}

- Studies that indirectly measured resilience ${ }^{13}$ or did not include a measure of resilience

- Studies that were not peer-reviewed manuscripts (e.g., dissertation abstracts) ${ }^{14}$ 
- Studies that included patients who did not undergo total joint arthroplasty ${ }^{15,16}$

\section{Evidence Quality Assessment}

The STrengthening the Reporting of Observational studies in Epidemiology (STROBE) Statement ${ }^{17}$ was used to examine the validity of the included studies. Item 22 was excluded from the quality assessment as it did not apply to the studies included in the CAT. Therefore, the highest score that could be obtained was a 21. Two authors (AS, JH) independently reviewed and appraised each study. After independent review, the two authors discussed the completed appraisals and reached an agreement about study quality.

\section{Results of Search}

\section{Summary of Search, Best Evidence Appraised, and Key Findings}

The original literature search produced seven studies (Figure 1). After review of abstracts, three ${ }^{14-16}$ studies were excluded. After review of the manuscripts, one study ${ }^{13}$ was excluded and three cohort studies that met the inclusion criteria for the CAT were included. ${ }^{5,8,9}$ Characteristics of each study are outlined in Table 1. All three studies evaluated the relationship between resilience and self-reported function after total joint arthroplasty.

Tokish et al. ${ }^{8}$ and Magaldi et al. ${ }^{9}$ used the BRS to measure resilience while Benditz et al. $^{5}$ utilized the RS-11 to measure resilience. One study included patients who underwent total shoulder arthroplasty and utilized the American Shoulder and Elbow Surgeons (ASES), Single Assessment Numeric Evaluation (SANE), and Penn Score to capture self-reported function. ${ }^{8}$ Another study evaluated the relationship in patients who underwent total knee arthroplasty, and the authors captured self-reported function using the Knee Injury and Osteoarthritis Outcome Score JR (KOOS-JR),

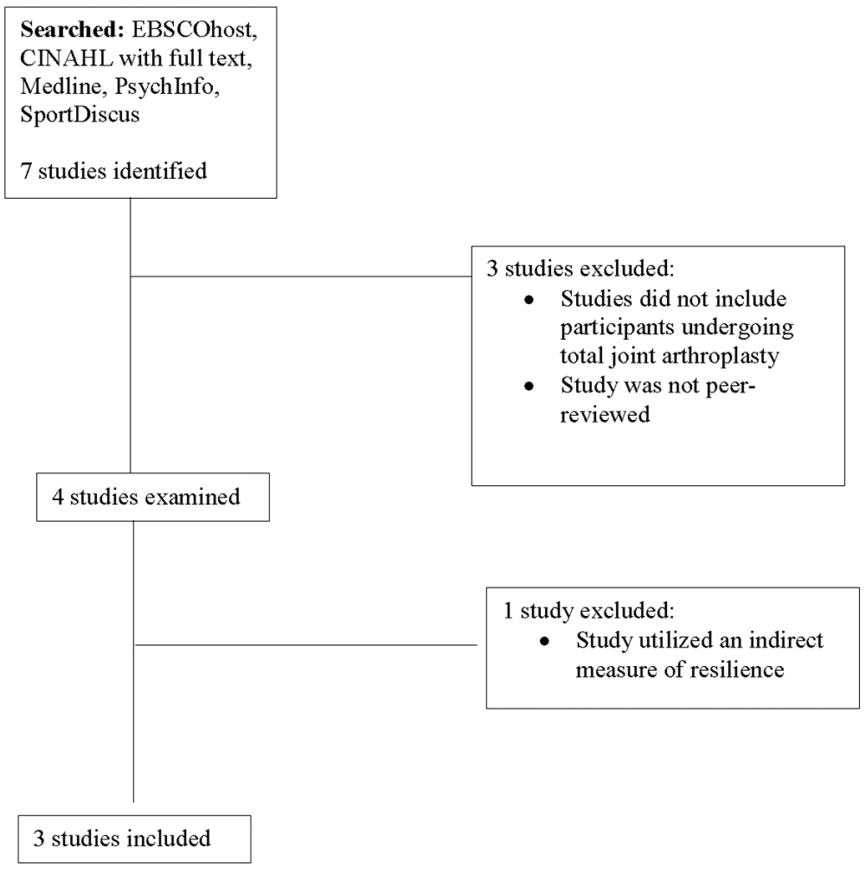

Figure 1 - Search strategy.
Patient-Reported Outcomes Measurement Information System (PROMIS-10), and EuroQol Group health-related quality of life measurement (EQ-5D). ${ }^{9}$ The final study measured the relationship between self-reported function and resilience in patients who underwent total hip arthroplasty and utilized the Harris Hip Score (HHS) to measure self-reported function. ${ }^{5}$ The results of Tokish et al. ${ }^{8}$ demonstrated that postoperative BRS correlated with ASES, Penn, and SANE scores approximately 2 years after total shoulder arthroplasty. The results of Magaldi et al. ${ }^{9}$ demonstrated an association between BRS, KOOS-JR, and PROMIS-10 scores at 3 months and 12 months postoperatively. Benditz et al. ${ }^{5}$ did not identify a relationship between resilience and HHS outcome scores.

\section{Results of Evidence Quality Assessment}

Tokish et al. ${ }^{8}$ scored a 16/21, while Magaldi et al. ${ }^{9}$ scored a 21/21, and Bendtiz et al..$^{5}$ scored a 20/21. Two studies included ${ }^{5,8}$ did not describe efforts to report potential sources of bias. Tokish et al. ${ }^{8}$ also did not provide a description of the setting, locations, and relevant dates regarding participant recruitment or follow-up, and details regarding participant numbers and reasons for nonparticipation, nor did they report descriptive data or other analyses done in the results.

\section{Clinical Bottom Line}

There is inconsistent, good-quality Level II evidence that investigates the relationship between resilience and self-reported function in patients after joint arthroplasty. Due to the inconsistency and level of evidence of the articles included in this CAT, grade B is recommended by the Strength of Recommendation Taxonomy. ${ }^{18}$

\section{Implications for Practice, Education, and Future Research}

The results of this critical appraisal revealed inconsistent, highquality Level II studies that suggest a relationship between resilience and self-reported function after total joint arthroplasty. Each study included a population undergoing a different total joint arthroplasty, and correlated resilience to different PROs. Tokish et al. ${ }^{8}$ evaluated the relationship between the $\mathrm{BRS}^{11}$ and the ASES, Penn, and SANE outcome measures 2 years after surgery. ${ }^{8}$ Magaldi et al. ${ }^{9}$ evaluated the relationship between the BRS and the KOOSJR, PROMIS-10, and EQ-5D to after total knee arthroplasty. ${ }^{9}$ Overall, they discovered a significant association between BRS scores, the KOOS-JR, and the PROMIS-10 at 3 months and 12 months postoperative. ${ }^{9}$ Finally, Benditz et al. ${ }^{5}$ measured the relationship the Resilience Scale (RS-11) ${ }^{19}$ and the self-reported hip function using the HHS after total hip arthroplasty. Both the RS-11 and HHS were administered before surgery, 1 week after surgery, and again at 5 weeks postoperatively. The results indicated no significant relationship between resilience and HHS scores. The researchers also concluded that resilience did not change significantly over the 5 weeks.

There was inconsistent results with the three included studies. Tokish et al. ${ }^{8}$ and Magaldi et al. ${ }^{9}$ identified a relationship between resilience and self-reported function, while Benditz et al..$^{5}$ identified no relationship in their population. These inconsistencies may be present for a multitude of reasons. First, all of the included studies utilized different time points to examine the relationship between 
Table 1 Characteristics of Included Studies

\begin{tabular}{|c|c|c|c|}
\hline Characteristics & Tokish et al. ${ }^{8}$ & Magaldi et al. ${ }^{9}$ & Benditz et al. ${ }^{5}$ \\
\hline Title & $\begin{array}{l}\text { Resilience correlates with outcomes after } \\
\text { total shoulder arthroplasty }\end{array}$ & $\begin{array}{l}\text { Impact of resilience on outcome of total } \\
\text { knee arthroplasty }\end{array}$ & $\begin{array}{l}\text { Psychological factors as risk factors for } \\
\text { poor hip function after total hip arthroplasty }\end{array}$ \\
\hline Participants & $\begin{array}{l}\text { Total of } 70 \text { ( } 19 \text { male } / 51 \text { female }) \\
\text { participants age } 65 \pm 10 \text { years }\end{array}$ & $\begin{array}{l}\text { Total of } 153(74 \text { male } / 79 \text { female) patients } \\
\text { aged } 68.2 \pm 8.3 \text { years with a body mass } \\
\text { index (BMI) of } 31.3 \pm 5.8\end{array}$ & $\begin{array}{l}50(23 \text { male/ } 27 \text { female }) \text { participants aged } \\
62.2 \pm 11.5 \text { years, height } 5.5 \pm 0.3 \mathrm{ft} \\
\text { BMI } 27.95 \pm 5.44\end{array}$ \\
\hline $\begin{array}{l}\text { Inclusion/Exclu- } \\
\text { sion Criteria }\end{array}$ & Not reported & $\begin{array}{l}\text { Inclusion: Patients } 18 \text { years or older } \\
\text { planning to undergo primary elective } \\
\text { total knee arthroplasty. } \\
\text { Exclusion: Those patients that planned to } \\
\text { have a second total knee replacement or } \\
\text { total hip replacement within } 6 \text { months of } \\
\text { the first procedure }\end{array}$ & $\begin{array}{l}\text { Inclusion: Between the ages of } 20-85 \\
\text { years; outcome measures taken within } 6 \\
\text { months of surgery; diagnosed osteoarthritis } \\
\text { of the hip; failed conservative treatments; } \\
\text { no history of previous hip surgery } \\
\text { Exclusion: Not reported }\end{array}$ \\
\hline $\begin{array}{l}\text { Outcome } \\
\text { Measures }\end{array}$ & $\begin{array}{l}\text { American Shoulder and Elbow Surgeons } \\
\text { (ASES), Single Assessment Numeric } \\
\text { Evaluation (SANE), Penn Score, } \\
\text { Brief Resilience Scale (BRS) }\end{array}$ & $\begin{array}{l}\text { Knee Injury and Osteoarthritis Outcome } \\
\text { Score-JR (KOOS-JR), Patient-Reported } \\
\text { Outcomes Measurement Information } \\
\text { System (PROMIS-10), EuroQol } \\
\text { Group health-related quality of life } \\
\text { measurement (EQ-5D), BRS }\end{array}$ & $\begin{array}{l}\text { Harris Hip Score (HHS); Resilience Scale } \\
\text { (RS-11); Allgemeine Depressionsskala } \\
\text { (general depression scale-long) (ADS-L); } \\
\text { State and Trait Anxiety Inventory (STAI); } \\
\text { Freiburg Personality Inventory-revised } \\
\text { (FPI-R) }\end{array}$ \\
\hline Results & $\begin{array}{l}\text { The average BRS score was } 20.4 \pm 3.7 \\
\text { points. Postoperative BRS scores sig- } \\
\text { nificantly correlated with ASES, Penn, } \\
\text { and SANE scores ( } r=.41-.44, p<.004) \text {. } \\
\text { Participants were separated in to three } \\
\text { groups: low resilience group (LR), } \\
\text { normal resilience group (NR), and high } \\
\text { resilience group (HR). The LR group had } \\
\text { Penn Scores that were } 34 \text { points lower } \\
\text { and SANE scores that were } 40 \text { points } \\
\text { lower than the HR group }(p=.05) \text {. }\end{array}$ & $\begin{array}{l}\text { For the KOOS-JR, the change in the } \\
\text { proportion of variance attributable to } \\
\text { resilience was } .10(p<.001) \text { at } 3 \text { months } \\
\text { and } .05(p=.006) \text { at } 12 \text { months. }\end{array}$ & $\begin{array}{l}\text { The average scores on the RS- } 11 \text { were } \\
59.86 \pm 11.0 \text { at preoperative, } 59.26 \pm 11.1 \\
\text { at } 1 \text { week postoperative, and } 59.74 \pm 11 \text { at } \\
5 \text { weeks postoperative. The average HHS } \\
\text { score at preoperative was } 49.66 \pm 19.9 \text {, } \\
60.0 \pm 14 \text { at } 1 \text { week postoperative, and } \\
73.3 \pm 8.8 \text { at } 5 \text { weeks postoperative. There } \\
\text { was no relationship identified between the } \\
\text { RS- } 11 \text { and the HHS. }\end{array}$ \\
\hline Level of Evidence & 2 & 1 & 1 \\
\hline STROBE Score & $16 / 21$ & $21 / 21$ & $20 / 21$ \\
\hline $\begin{array}{l}\text { Support for the } \\
\text { Answer }\end{array}$ & Yes & Yes & No \\
\hline
\end{tabular}

resilience and self-reported function. The only study that did not identify a relationship was Benditz et al., ${ }^{5}$ and this may be because the timeline was relatively short (maximum 5 weeks). The authors utilized these timepoints to attempt to prevent influences from the home environment on outcome scores, as the patients were in an inpatient facility for the entire data collection period. This 5-week timeline is in contrast to the other two included studies, which identified a positive correlation in self-reported function and resilience. Magaldi et al. ${ }^{9}$ included a time-point of 3 months and 12 months and Tokish et al. ${ }^{8}$ included a time-point of 2 years. Although the researchers used this timeline to eliminate bias, 5 weeks may be too short to determine whether or not individuals will be able to adapt and overcome from their surgery. Furthermore, we believe these results may also indicate the importance of social and familial support on outcomes. ${ }^{10}$ Perhaps over time, resilience in this population would be impacted by returning home and gaining back social and familial support that is imperative to positive outcomes after rehabilitation.

Another difference between the studies was the resilience scales used. Tokish et al. ${ }^{8}$ and Magaldi et al. ${ }^{9}$ used the BRS. The BRS consists of six questions scored on a Likert scale where higher scores indicate higher resilience. ${ }^{11}$ This scale was developed to assess the ability to "bounce back or recover from stress." "It has been validated for multiple populations such as students and those suffering from chronic illness. ${ }^{6,11}$ Previous research has determined this scale is valid and reliable. ${ }^{6,11}$ Benditz et al. ${ }^{5}$ used the RS- 11 . The RS-11 is a shortened version of the Resilience Scale created by Wagnild and Young. ${ }^{19}$ Similar to the BRS, this 11-question survey is scored with a Likert scale, with a higher score representing higher resilience. ${ }^{19}$ The RS-11 was developed using data from 24 women who survived a traumatic event. ${ }^{6,19}$ However, it has been applied to other populations such as adolescents and young adults, ${ }^{6}$ and has been used to evaluate overall health and depression in the older adult population. ${ }^{19}$ It has been suggested that the RS-11 may not have been an appropriate measure to capture resilience in previous research $^{6}$; however, the scale has been utilized previously with a variety of patient populations. ${ }^{20-24}$ Therefore, we must also take in to account the differences in the measures used and the psychometric development of these measures when examining the inconsistent evidence included in this CAT.

Although the results of the three studies appraised in this CAT are inconsistent, two studies did suggest that resilience is correlated to self-reported function after total joint arthroplasty. In the future, researchers should use validated and reliable scales such as the $\mathrm{BRS}^{6,11}$ to measure resilience in patients undergoing total joint arthroplasty. Patients should also be followed longitudinally, through the immediate postoperative phase until the final followup. Longitudinal studies will provide more insight into how the patient's function and quality of life changes throughout the rehabilitation process, but they may also evaluate the change in 
resilience that patients may experience over time. While existing literature has examined resilience factors in a population with a history of ACL reconstruction, ${ }^{10}$ this was qualitative in nature and did not include a subject measure of resilience. Future studies should include a quantitative analysis of resilience in younger populations who are undergoing other types of surgeries, such as ACL reconstruction or shoulder surgery.

Osteoarthritis is a debilitating disease that can sometimes progress to require total joint replacement surgery. ${ }^{3}$ Psychological factors, such as resilience, may influence outcomes after total joint arthroplasty. Healthcare providers should consider assessing resilience as an additional psychological factor that may impact selfreported function in this population. While this CAT suggests an inconsistent relationship between self-reported function and resilience in this population, future research should continue to investigate this relationship.

\section{CAT Kill Date: March 2023}

CATs have a limited life and should be revisited approximately 2 years after publication (see https://doi.org/10.1123/ijatt.2018-0093).

\section{References}

1. Kim C, Linsenmeyer KD, Vlad SC, et al. Prevalence of radiographic and symptomatic hip osteoarthritis in an urban United States community: the Framingham osteoarthritis study. Arthritis Rheumatol. 2014;66(11):3013-3017. PubMed ID: 25103598 doi:10.1002/art. 38795

2. Memel DS, Kirwan JR, Sharp DJ, Hehir M. General practitioners miss disability and anxiety as well as depression in their patients with osteoarthritis. Br J Gen Pract. 2000;50(457):645-648. PubMed ID: 11042917

3. Jonsson H, Olafsdottir S, Sigurdardottir S, et al. Incidence and prevalence of total joint replacements due to osteoarthritis in the elderly: risk factors and factors associated with late life prevalence in the AGES- Reykjavik Study. BMC Musculoskelet Disord. 2016; 17:14. PubMed ID: 26759053 doi:10.1186/s12891-016-0864-7

4. Whiteford HA, Ferrari AJ, Degenhardt L, Feigin V, Vos T. The global burden of mental, neurological and substance use disorders: an analysis from the Global Burden of Disease Study 2010. PLoS One. 2015;10(2):e0116820. PubMed ID: 25658103 doi:10.1371/ journal.pone. 0116820

5. Benditz A, Jansen P, Schaible J, Roll C, Grifka J, Götz J. Psychological factors as risk factors for poor hip function after total hip arthroplasty. Ther Clin Risk Manag. 2017;13:237-244. PubMed ID: 28260910 doi:10.2147/TCRM.S127868

6. Windle G, Bennett KM, Noyes J. A methodological review of resilience measurement scales. Health Qual Life Outcomes. 2011; 9(1):8. doi:10.1186/1477-7525-9-8

7. Ursano RJ, Colpe LJ, Heeringa SG, et al. The Army study to assess risk and resilience in servicemembers (Army STARRS). Psychiatry. 2014;77(2):107-119. PubMed ID: 24865195 doi:10.1521/psyc.2014. 77.2.107

8. Tokish JM, Kissenberth MJ, Tolan SJ, et al. Resilience correlates with outcomes after total shoulder arthroplasty. J Shoulder Elbow Surg. 2017;26(5):752-756. PubMed ID: 28190668 doi:10.1016/j.jse.2016. 12.070

9. Magaldi RJ, Staff I, Stovall AE, Stohler SA, Lewis CG. Impact of resilience on outcomes of total knee arthroplasty. J Arthroplasty. 2019;34(11):2620-2623.e1. PubMed ID: 31278038 doi:10.1016/j. arth.2019.06.008

10. Johnson U, Ivarsson A, Karlsson J, Hagglund M, Walden M, Borjesson M. Rehabilitation after first-time anterior cruciate ligament injury and reconstruction in female football players: a study of resilience factors. BMC Sports Sci Med Rehabil. 2016;8:20. PubMed ID: 27429759 doi:10.1186/s13102-016-0046-9

11. Smith BW, Dalen J, Wiggins K, Tooley E, Christopher P, Bernard J. The brief resilience scale: assessing the ability to bounce back. Int J Behav Med. 2008;15(3):194-200. PubMed ID: 18696313 doi:10. 1080/10705500802222972

12. Connor KM, Davidson JR. Development of a new resilience scale: the Connor-Davidson Resilience Scale (CD-RISC). Depress Anxiety. 2003;18(2):76-82. PubMed ID: 12964174 doi:10.1002/da.10113

13. Cremeans-Smith JK, Greene K, Delahanty DL. Trauma history as a resilience factor for patients recovering from total knee replacement surgery. Psychol Health. 2015;30(9):1005-1016. doi:10.1080/ 08870446.2014.1001391

14. Krackow A. Hardiness and dispositional optimism: predictors of outcome in total joint athroplasty. Dissertation Abstracts International: Section B: The Sciences and Engineering. 1996;57(5-B):3444.

15. Sciume L, Rebagliati GAA, Iannello P, et al. Rehabilitation after urgent or elective orthopedic surgery: the role of resilience in elderly patients. Rehabilitation Nursing. 2018;43(5):267-274. PubMed ID: 30168809

16. Lawrenz JM, Higuera CA, Mollor RM, Simpfendorfer C, Babi M. Treatment challenges of prosthetic hip infection with associated iliacus muscle abscess: report of 5 cases and literature review. $J$ Bone Joint Infect. 2017;2(3):127-135. doi:10.7150/jbji.16429

17. Von Elm E, Altman DG, Egger M, Pocock SJ, Gøtzsche PC, Vandenbroucke JP. The Strengthening the Reporting of Observational Studies in Epidemiology (STROBE) statement: guidelines for reporting observational studies. Ann Intern Med. 2007;147(8): 573-577. PubMed ID: 17938396 doi:10.7326/0003-4819-147-8200710160-00010

18. Ebell MH, Siwek J, Weiss BD, et al. Strength of recommendation taxonomy (SORT): a patient-centered approach to grading evidence in the medical literature. J Am Board Fam Pract. 2004;17(1):59-67. PubMed ID: 15014055 doi:10.3122/jabfm.17.1.59

19. Wagnild G, Young H. Development and psychometric. J Nurs Meas. 1993;1(2):165-17847. PubMed ID: 7850498

20. Wesemann W, Willmund GD, Ungerer J, et al. Assessing psychological fitness in the military- development of an effective economic screening instrument. Mil Med. 2018;183(7-8):e261-e269. PubMed ID: 29596663 doi:10.1093/milmed/usy021

21. Cosco T, Kaushal A, Richards M, Kuh D, Stafford M. Resilience measurement in later life: a systematic review and pyschometric analysis. Health Qual Life Outcomes. 2016;14(1):16. doi:10.1186/ s12955-016-0418-6

22. Beutel ME, Glaesmer H, Decker O, Fishbeck S, Brahler E. Life satisfaction, distress, and resiliency across the life span of women. Menopause. 2009;16(6):1132-1138. PubMed ID: 19543128 doi:10. 1097/gme.0b013e3181a857f8

23. Kocalevent RD, Zenger M, Heinen I, Dwinger S, Decker O, Brahler E. Resilience in the general population: standardization of the resilience scale (RS-11). PLoS One. 2015;10(11): e0140322. PubMed ID: 26523927 doi:10.1371/journal.pone.0140322

24. von Eisenhart Rothe A, Zenger M, Lacruz ME, et al. Validation and devleopment of a shorter version of the resilience scale RS-11: results from the population-based KORA-age study. BMC Psychology. 2013;1(1):25. doi:10.1186/2050-7283-1-25 